ORIGINAL ARTICLE

\title{
Ventilation strategies and outcome in randomised trials of high frequency ventilation
}

\author{
U H Thome, W A Carlo, F Pohlandt
}

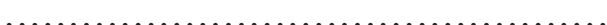

Arch Dis Child Fetal Neonatal Ed 2005;90:F466-F473. doi: 10.1136/adc.2004.068437 See end of article for
authors' affiliations

Correspondence to: Ulrich Thome, Division of Neonatology and Paediatric Critical Care University Children's Hospital, 89070 Ulm, Germany; ulrich.thome@ gmx.net

Accepted 19 May 2005 Published Online First 7 June 2005

\begin{abstract}
Objective: Randomised controlled trials comparing elective use of high frequency ventilation (HFV) with conventional mechanical ventilation (CMV) in preterm infants have yielded conflicting results. We hypothesised that the variability of results may be explained by differences in study design, ventilation strategies, delay in initiation of HFV, and use of permissive hypercapnia.

Methods: Randomised controlled trials comparing the elective use of HFV with any form of CMV were identified. Trials were classified according to the ventilation strategies used for HFV and CMV and oscillator device employed. For cumulative meta-analyses, trials were arranged by the following covariables: mean duration until randomisation, $\mathrm{Paco}_{2}$ limits, publication date, and sample size. Odds ratios (OR) and $95 \%$ confidence intervals were calculated using fixed and random effects models.

Results: Seventeen randomised trials enrolling 3776 patients were included. Unlike previous metaanalyses, there was no significant difference in the incidence of bronchopulmonary dysplasia or death (OR $0.87,0.75-1.00)$ and severe intraventricular haemorrhage grade $3-4(1.14,0.96-1.37)$. The incidence of air leaks (OR 1.23, 1.06-1.44) was significantly increased with HFV. Subgroup analyses and cumulative meta-analyses demonstrated that trial results were related to the ventilation strategies used for HFV and CMV. No influence was found for mean time to randomisation, degree of permissive hypercapnia, or sample size.

Conclusions: Heterogeneity among trials of elective HFV compared to CMV in preterm infants is mainly due to differences in ventilatory strategies. Optimising CMV strategy appeared to be as effective as using HFV in improving pulmonary outcome in preterm infants.
\end{abstract}

A n extensive literature supports the concept that ventilation with relatively large tidal volumes can result in lung injury. ${ }^{1}$ It is possible to preserve the desired minute ventilation by using relatively small tidal volumes and a high ventilatory rate. Three randomised trials have shown that conventional mechanical ventilation (CMV) with higher ventilatory rates $(60 / \mathrm{min} v 20-40 / \mathrm{min})$ reduces the incidence of air leaks and may even decrease mortality. ${ }^{2-4}$ However, all three studies were performed in the presurfactant era. Another way to minimise lung injury may be to reduce tidal volume at the expense of minute ventilation while accepting higher arterial $\mathrm{CO}_{2}$ tension. ${ }^{5-7}$

The use of high ventilatory rates during CMV is limited by the minimum amount of time needed for a complete inspiration and expiration. New technologies to further increase the ventilatory rate and reduce the tidal volume led to the development of high frequency ventilation (HFV), which has been studied extensively in premature infants but with conflicting results. ${ }^{8-24}$ Comparability between trials is limited by differences in ventilatory strategies, time between birth and randomisation, ventilator technology, patient population, study end points, and use of antenatal steroids and surfactant. Preferring higher ventilation rates during $\mathrm{CMV}^{2-4}$ and permissive hypercapnia ${ }^{5}$ may have benefited the control groups in some studies and thereby diminished the advantage of HFV. The most extensively discussed reasons for conflicting results included the ventilation strategies used for $\mathrm{HFV}^{25}$ and CMV, ${ }^{17}{ }^{26}$ the age when HFV was started, ${ }^{27}$ and the ventilator technology and devices used. ${ }^{28}$

Two opposing strategies are possible when applying HFV. Mean pressure and lung inflation can be minimised, but higher inspired oxygen concentrations may be necessary (low lung volume strategy, LLVS). On the other hand, with higher mean airway pressure, recruitment of alveoli and elimination of atelectasis tend to improve oxygenation by increasing lung surface area and eliminating intrapulmonary shunts (high lung volume strategy, HLVS). Animal experiments indicate better short term results after using an HLVS..$^{29-31}$

Herein, we present an in depth meta-analysis of all available randomised trials comparing elective HFV with CMV, including three trials ${ }^{1922}{ }^{24}$ not yet included in the latest Cochrane reviews. ${ }^{32}{ }^{33}$ We use cumulative ${ }^{34}$ and recursivecumulative meta-analyses ${ }^{35-37}$ to determine if the following covariates and study design differences may have influenced whether or not trials found a significant advantage associated with HFV:
1. Publication date
2. Use of surfactant
3. High frequency ventilation strategy
4. Conventional ventilation strategy
5. Overall outcome
6. Delay before starting randomised ventilation mode
7. $\mathrm{PaCO}_{2}$ targets (use of permissive hypercapnia)
8. Sample size of the individual trials

Abbreviations: BPD28, bronchopulmonary dysplasia, defined as persistent requirement for supplemental oxygen or mechanical ventilation at a postnatal age of 28-30 days; BPD36,

bronchopulmonary dysplasia, defined as persistent requirement for supplemental oxygen or mechanical ventilation at a postmenstrual age of 36-37 weeks; CMV, conventional mechanical ventilation; HFJV, high frequency jet ventilation; HFOV, high frequency oscillatory ventilation; HFPPV, high frequency positive pressure ventilation; HFV, high frequency ventilation; HLVS, high lung volume strategy; IVH 3-4, intraventricular haemorrhage grade 3 or 4 ; LLVS, low lung volume strategy; LPVS, low pressure volume strategy for CMV; OR, odds ratio; $P V L$, periventricular leukomalacia; RDS, respiratory distress syndrome 


\section{METHODS}

A MEDLINE search was undertaken to identify randomised controlled trials that compared HFV with CMV in preterm infants requiring mechanical ventilation mainly due to respiratory distress syndrome (RDS). Further, the abstract books of the recent Pediatric Academic Societies Meetings (1995-2004) were hand searched to identify trials not published in final form.

Trials attempting to include all infants showing a certain degree of RDS as soon as possible after the start of CMV and usually within the first $24 \mathrm{~h}$ of life were classified as elective and incorporated into the meta-analysis. Furthermore, the randomly assigned mode had to be sustained for at least 5 days or until extubation. Both criteria limited exposure of participants to the alternate ventilation mode during the early phase of lung disease. Trials including only patients showing signs of treatment failure or developing complications were classified as rescue, and excluded from the metaanalysis.

The following outcomes were selected for further evaluation: mortality until 36 weeks postmenstrual age, bronchopulmonary dysplasia (defined as oxygen and/or ventilator dependency at age 28-30 days (BPD28) or at 36-37 weeks postmenstrual age (BPD36)), BPD28 or death at age 28 30 days, BPD36 or death at 36-37 weeks postmenstrual age, air leaks (pulmonary interstitial emphysema or gross air leaks), intraventricular haemorrhage (IVH) grades 3-4, according to Papile et $a l^{38}$ and periventricular leukomalacia (PVL).

To determine the influence of ventilatory strategy or technology, trials were subdivided into the following subgroups:

- High lung volume strategy (HLVS); the ventilatory strategy in the HFV group included lung volume optimisation.

- SensorMedics 3100A (SM3100); at least $80 \%$ of patients randomised to HFV were treated with the SensorMedics 3100A device (VIASYS, Yorba Linda, CA, USA).

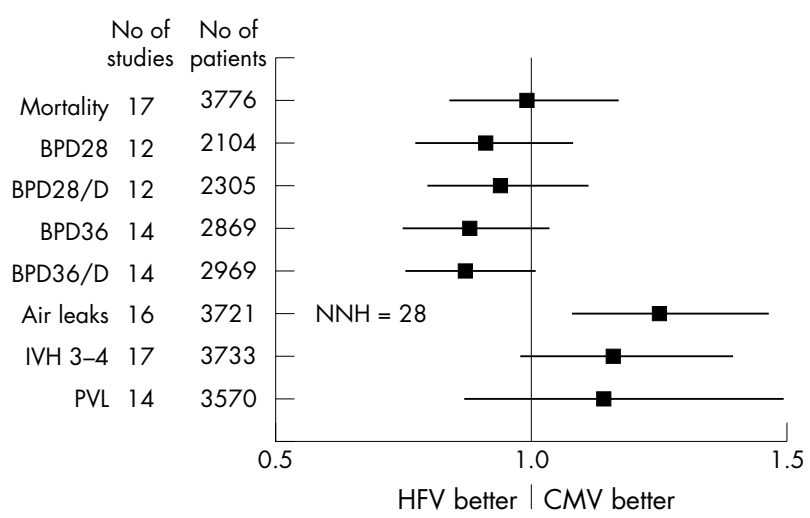

Figure 1 Overall results showing odds ratios and $95 \%$ confidence intervals, calculated according to a fixed effect model, for the analysed outcome parameters. The significant difference in the incidence of air leaks remained significant in a random effects model. Air leaks: pneumothorax, pneumomediastinum, or pulmonary interstitial emphysema; BPD28: bronchopulmonary dysplasia, defined as oxygen or ventilator dependency at 28 days postnatal age; BPD28/D: BPD28 or death; BPD36: bronchopulmonary dysplasia, defined as oxygen or ventilator dependency at 36 weeks postmenstrual age; BPD36/D: BPD36 or death; IVH 3-4: intraventricular haemorrhage grade 3 to 4 according to Papile et a ${ }^{\beta 3}$; NNH: number needed to harm; PVL: periventricular leukomalacia.
- Low pressure and volume strategy (LPVS); the ventilatory strategy in the CMV group aimed at lowering tidal volumes by specifying

- a) a high lower limit for arterial carbon dioxide $\left(\mathrm{PaCO}_{2}\right.$ $\geqslant 40 \mathrm{~mm} \mathrm{Hg}$ ),

- b) upper limits for tidal volumes $\leqslant 6 \mathrm{ml} / \mathrm{kg}$, and

- c) a high ventilatory rate $(\geqslant 60 / \mathrm{m}$, high frequency positive pressure ventilation (HFPPV)). ${ }^{2-4}$

The influence of the continuous covariates, time between birth and randomisation, $\mathrm{PaCO}_{2}$ limits, and sample size of the trials was determined by cumulative meta-analyses as described. ${ }^{34}$ The trials were ordered by ascending time to randomisation, descending $\mathrm{PaCO}_{2}$ limits, or ascending sample size. Odds ratios of the risk of BPD36 or death were determined for the first trial of the lists, then for the first and second combined, and so on, until all were included.

The recursive cumulative meta-analysis consisted of two steps. ${ }^{35}{ }^{36}$ First, trials were ordered by publication date and a cumulative meta-analysis was done. ${ }^{34}$ For the recursive analysis, the relative change of the odds ratio incurred with the addition of each individual trial, equivalent to the first derivative of the odds ratio, was calculated and graphically displayed.

Calculations of the odds ratios according to the fixed effect model of Mantel and Haenszel ${ }^{39}$ were done with SAS Software (SAS Institute, Cary, NC, USA). Review Manager and RevMan Analyses software (The Cochrane Collaboration, Oxford, England) were used for random effects model calculations according to DerSimonian and Laird ${ }^{40}$ when necessary.

\section{RESULTS}

Seventeen trials with a combined total of 3776 patients met the inclusion criteria for the meta-analysis. ${ }^{8-24}$ Data were generally extracted from the publications, with the following exceptions. Data about additional patients enrolled in the

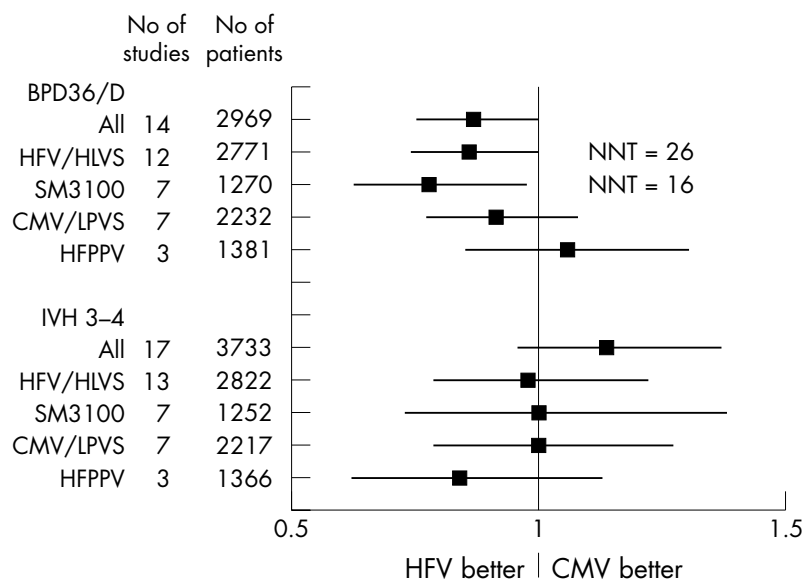

Figure 2 Results of subgroup analyses for the incidence of bronchopulmonary dysplasia, defined as oxygen or ventilator dependency at 36 weeks postmenstrual age or death (BPD36/D) and intraventricular haemorrhage grade 3 to 4 (IVH 3-4), according to Papile et $a l_{1}^{38}$ in a fixed effect model. The differences in the HFV/HLVS and SM3100 subgroups were no longer significant in a random effects model. All: all available studies included ${ }^{11-24}$; CMV/LPVS: only studies using a low pressure and tidal volume strategy for $\mathrm{CMV}^{17-23} ; \mathrm{HFPPV}$ : only studies using a high rate low pressure and tidal volume strategy for $\mathrm{CMV}^{17} 21{ }^{23}$; HFV/HLVS: only studies using an HLVS for HFV $\mathrm{HF}^{11} 121416-24$ NNT: number needed to treat; SM3100: only studies using the SensorMedics 3100A for HFV. ${ }^{11} 121619202324$ 


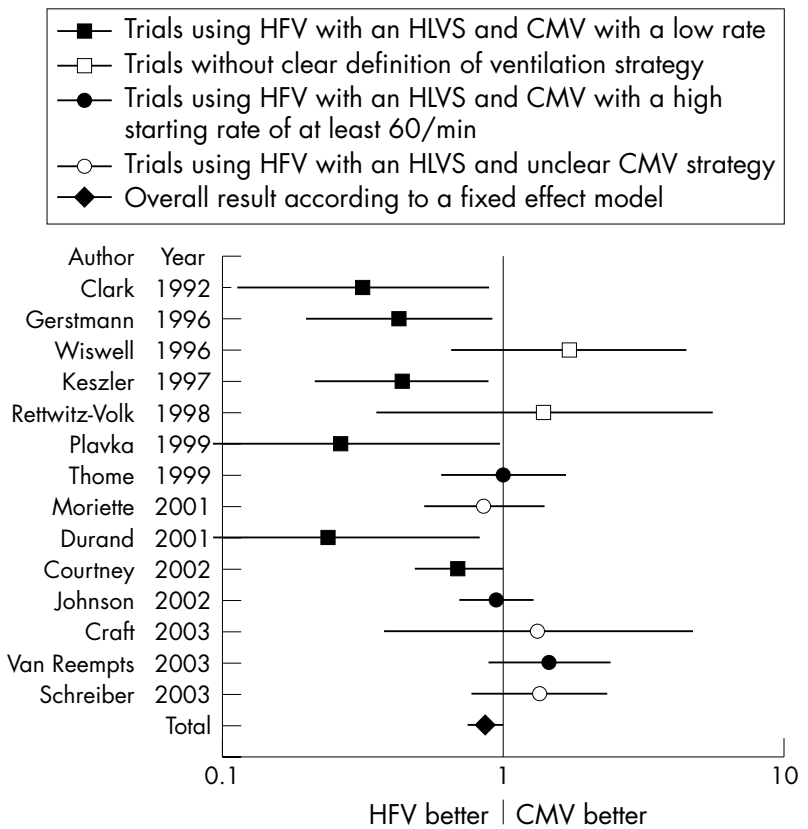

Figure 3 Individual study results for the incidence of bronchopulmonary dysplasia, defined as oxygen or ventilator dependency at 36 weeks postmenstrual age or death (BPD36/D). Trials are ordered by the publication year and identified by the first author names. ${ }^{1-24}$

study of Clark et al," who had been excluded after randomisation, were found in the Cochrane database. ${ }^{32}$ We included these data so we could do an intention-to-treat analysis. The third group of patients in this study, receiving HFV only for $72 \mathrm{~h}$, was not included. Additional data from the study of Gerstmann et $a l^{12}$ about the incidence of bronchopulmonary dysplasia at 36 weeks postmenstrual age were found in a review article by the same authors. ${ }^{28}$ Data from the study of Keszler et al, ${ }^{14}$ which used different HFV strategies in different study centres, was included in the subgroups as appropriate. Dr Schreiber kindly provided unpublished data from his study. ${ }^{24}$ The trials differed markedly in patient demographics, time of randomisation, ventilation strategies and devices used in both the HFV and CMV groups, sample size, use of surfactant, and reported outcomes (table 1). A funnel plot did not indicate publication bias.

Overall results are shown in fig 1 . As not all outcome parameters were available from all studies, the analysis of some outcomes had to be based on fewer trials. Most importantly, BPD36 was not reported in the HIFI trial, ${ }^{8}$ which reduced the sample size for this outcome. There was no statistically significant difference regarding mortality, BPD28, BPD28 combined with mortality, severe intraventricular haemorrhages (IVH 3-4), or PVL by either fixed or random effects models. Trends favouring HFV were observed for BPD36 and BPD36 or death, which, however, did not achieve statistical significance. HFV was significantly associated with an increase in air leaks in the fixed and random effects models.

For brevity, subgroup analyses are only shown for BPD36 or death and IVH 3-4 (fig 2). After limiting the analysis to trials using an HLVS or to trials using the SensorMedics $3100 \mathrm{~A}$ for HFV, the reduction of BPD or death became marginally significant in the fixed effect model only. However, when the subgroup analysis was limited to studies which also optimised their CMV by using a low pressure or tidal volume strategy (LPVS), there was no longer a significant difference, even though all studies in this subgroup used an HLVS for HFV. When the analysis was further limited to trials using a high rate low tidal volume strategy for CMV (HFPPV), there was a trend in the opposite direction, favouring HFPPV over HFV. A non-significant trend towards more IVH grade 3-4 with HFV in the overall analysis completely disappeared when limiting the analysis to trials using an HLVS.

Individual study results for the BPD36 or death outcome are shown in fig 3. Only trials using an HLVS for HFV, while limiting CMV to rates lower than $60 / \mathrm{min}$, yielded significant results favouring HFV. Plotting rates of survival without BPD36 against birth weight (fig 4) accounts for varying baseline data, and indicates that studies which show a difference between HFV and CMV 111214161920 invariably had CMV results below the regression line indicating the average outcome, whereas their HFV results were not better than the CMV results of several other studies showing no advantage of HFV. 13151723

The recursive cumulative meta-analysis shows the relative changes of the odds ratio after stepwise analysis including more and more data (fig 5). Along with fig 3, fig 5 also allows analysis by publication date, as trials are ordered chronologically. It appears that the early advantage seen with HFV diminished as time went on and more and more evidence was added. Therefore, the relative change of the odds ratio (dashed line) is mainly above unity. Three distinct peaks in the relative change can de discerned, indicating a strong movement of the cumulative odds ratio towards unity caused by the studies included at these points. Surfactant replacement therapy and high rate CMV appear to be important factors in this process because their introduction was associated with these rather strong movements of the odds ratio towards unity.

A cumulative meta-analysis with trials ordered by the time elapsed before randomisation and commencement of the randomised ventilation mode (fig 6) explores whether achieving the best results with HFV is dependent on reducing the preceding exposure to CMV. ${ }^{27}$ The odds ratio, however, does not show a clear pattern but undulates several times on either side of unity.

Following speculation that permissive hypercapnia helps CMV more than HFV to improve pulmonary outcome, ${ }^{17}$ we also performed a cumulative meta-analysis, with trials ordered by the $\mathrm{Paco}_{2}$ limits (fig 7), which also shows a non-conclusive undulating pattern. Similarly, a cumulative analysis with trials ordered by ascending sample size (fig 8) does not indicate any influence of sample size on trial outcome.

\section{DISCUSSION}

This meta-analysis is distinguished from previous ones $^{263233} 3741$ by a higher number of included trials and assessment of possible confounders by cumulative techniques. All randomised controlled trials on elective use of HFV for preterm infants available to date have been included. Furthermore, we have extensively used the techniques of cumulative meta-analysis ${ }^{34}$ and recursive cumulative metaanalysis $^{35}{ }^{36}$ to gain additional insight into the influence of covariates, previously claimed to be important for evaluating HFV trials, on the outcomes of individual trials as well as the meta-analyses.

With all 17 trials and 3776 patients included, there were no significant differences except for an increase in air leaks associated with HFV, which is in contrast to previous metaanalyses based on less data..$^{26} 323374$ The trends towards fewer cases of BPD and more cases of severe IVH were not significant despite the high number of trials and patients. Funnel plots do not indicate publication bias, but at least one 
Table 1 Studies included in this meta-analysis of elective use of HFV in preterm infants

\begin{tabular}{|c|c|c|c|c|c|c|c|c|}
\hline Study & $\mathbf{n}$ & $\begin{array}{l}\text { Ventilation } \\
\text { mode }\end{array}$ & $\begin{array}{l}\text { Gestional } \\
\text { age (weeks) }\end{array}$ & Birth weight (g) & $\begin{array}{l}\text { Age at random- } \\
\text { isation }(\mathrm{h}) \dagger\end{array}$ & Surfactant & $\begin{array}{l}\text { HFV with } \\
\text { HLVS }\end{array}$ & $\begin{array}{l}\text { CMV with } \\
\text { LPVS }\end{array}$ \\
\hline HIFI $1989^{8}$ & 673 & HFOV & $28 \pm 2$ & $1088 \pm 563$ & $6.1 \pm 4.6$ & No & $\mathrm{No}^{*}$ & $?$ \\
\hline Carlo $1990^{\circ}$ & 42 & HFJV & $30 \pm 2$ & $1418 \pm 296$ & $15.5(4-30)$ & No & No & Not \\
\hline Clark $1992^{11}$ & 65 & HFOV & $28 \pm 3$ & $1080 \pm 325$ & $9 \pm 5$ & No & Yes & Not \\
\hline Ogawa $1993^{10}$ & 92 & HFOV & $29 \pm 2$ & $1251 \pm 320$ & $2.0 \pm 1.6$ & Yes & Yes & $?$ \\
\hline Gerstmann $1996^{12}$ & 125 & HFOV & $30 \pm 2$ & $1510 \pm 465$ & $2.9(2.4-3.3)$ & Yes & Yes & Not \\
\hline Wiswell $1996^{13}$ & 73 & HFJV & $27 \pm 3$ & $946 \pm 267$ & $7.3 \pm 5.5$ & Yes & No & $?$ \\
\hline Keszler $1997^{14}$ & 130 & HFJV & $27 \pm 2$ & $1020 \pm 214$ & $8.1 \pm 4.2$ & Yes & In part & $?$ \\
\hline Rettwitz-Volk $1998^{15}$ & 96 & HFOV & $29 \pm 1$ & $1109 \pm 114$ & $<2$ & Yes & No & No \\
\hline Plavka $1999^{16}$ & 43 & HFOV & $26 \pm 2$ & $838 \pm 183$ & $<0.3$ & Yes & Yes & No \\
\hline Thome $1999^{17}$ & 284 & HFOV & $27 \pm 2$ & $901 \pm 251$ & $0.5 \pm 0.35$ & Yes & Yes & Yesł \\
\hline Moriette $2001^{18}$ & 273 & HFOV & $24-30$ & $980 \pm 229$ & $2.5 \pm 3$ & Yes & Yes & Yesł \\
\hline Durand $2001^{19}$ & 48 & HFOV & $26 \pm 2$ & $840 \pm 211$ & $2.6 \pm 1.1$ & Yes & Yes & Yesł§ \\
\hline Courtney $2002^{20}$ & 498 & HFOV & $26 \pm 1.6$ & $854 \pm 160$ & $2.7 \pm 0.9$ & Yes & Yes & Yesł§ \\
\hline Johnson $2002^{21}$ & 797 & HFOV & $26.5 \pm ?$ & $853 \pm 185$ & $<1$ & Yes & Yes & Yes \\
\hline Craft $2003^{22}$ & 46 & HFOV & $26(23-30)$ & $726(751-1000)$ & $?$ & Yes & Yes & Yesł \\
\hline Van Reempts $2003^{23}$ & 241 & HFOV & $29(25-32)$ & $1173(400-2292)$ & 0.9 & Yes & Yes & Yes \\
\hline Schreiber $2003^{24}$ & 207 & HFOV & $27.2 \pm 2.6$ & $983 \pm 379$ & $<12$ & Yes & Yes & No \\
\hline
\end{tabular}

trial was not included because of lack of access to the data. ${ }^{42}$ This trial apparently did not find a difference in favour of HFV and thus would probably not change the overall results if it was included.

In the subgroup of trials using HFV with an HLVS and the subgroup using only the SM3100 with an HLVS, the trend towards less cases of BPD or death became significant. This finding, however, must be interpreted with great caution for two reasons. First, when measures were taken to optimise CMV, as in the trials using an LPVS strategy with CMV, the advantage of HFV disappeared, and was even replaced by a trend in the opposite direction in the subgroup of trials using HFPPV, despite the continued use of an HLVS for HFV in these trials (fig 3). A similar pattern was found among the studies using the SM3100 for HFV. Most found an advantage associated with HFV but did not use an LPVS or HFPPV strategy for CMV. The only direct comparison between HFV using the SM3100 device with an HLVS, and CMV with HFPPV, performed by van Reempts et $a l,^{23}$ did not demonstrate any benefit associated with HFV (fig 3) while achieving a very low rate of adverse outcomes (fig 4). Second, statistical significance in the HLVS and SM3100 subgroups was only achieved with the fixed effect model, which assumes that the effect size in all studies is the same. However, a random effects model, which assumes a distribution of effect sizes, may be more appropriate, because different ventilatory strategies were used and significant results were found in the test for heterogeneity. Differences that are not robust to the random effects model may not be relevant under such circumstances.

With time, the odds ratio of BPD or death moved towards unity, thus diminishing the initial advantage of HFV, which may reflect the improvement in conventional respiratory care. In the recursive cumulative meta-analysis (fig 5), the

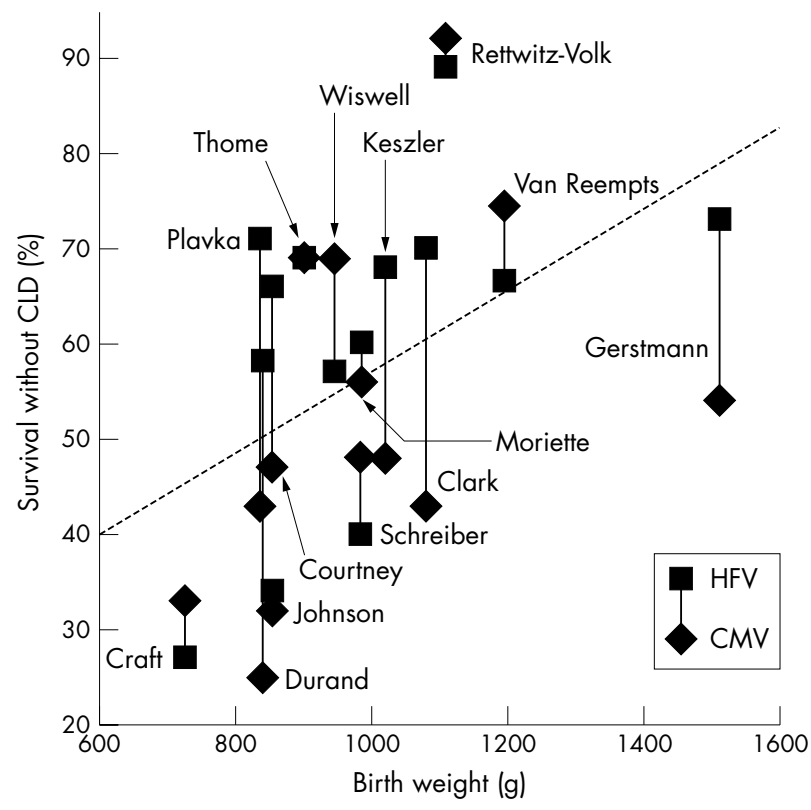

Figure 4 Plot of survival without BPD at 36 weeks postmenstrual age in the HFV and CMV randomisation groups by mean birth weight of all studies reporting that outcome. Trials are identified by the first author names. ${ }^{11-24}$ The dotted line is the overall linear regression line. 


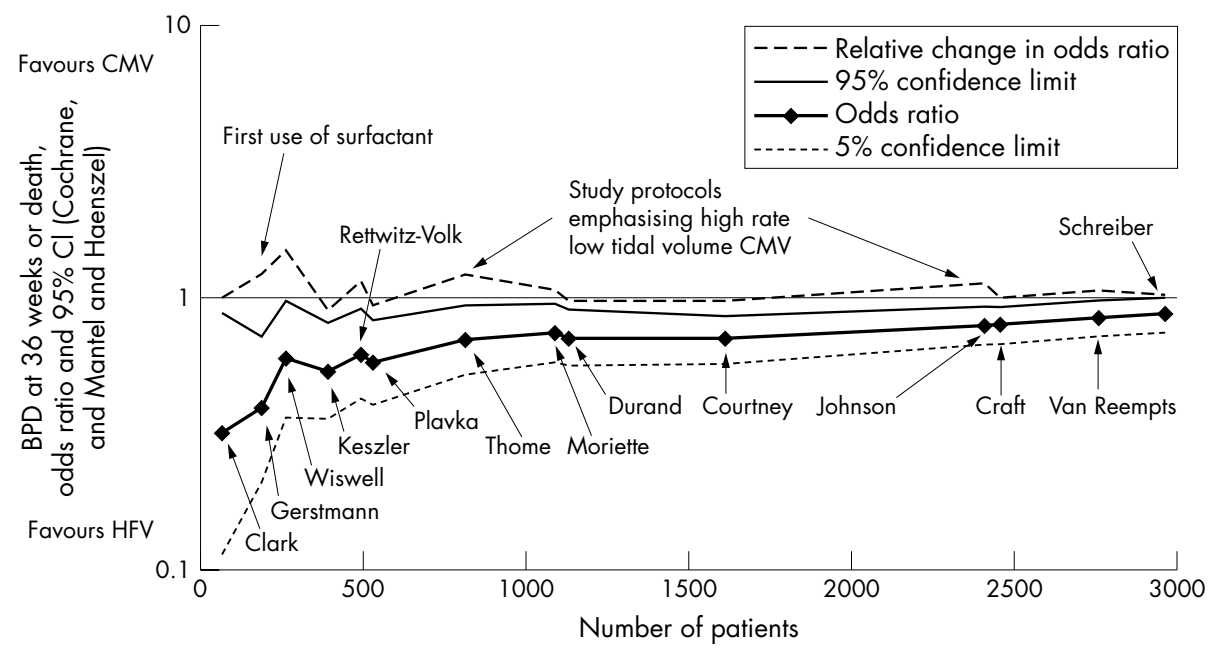

Figure 5 Recursive cumulative meta-analysis showing the relative change of the odds ratio (dashed line), also called cumulative treatment effect ratio, after each additional trial was included. Also shown are odds ratio, calculated according to a fixed effect model, and $95 \%$ confidence intervals. With the last study included, the $95 \%$ confidence boundary crossed unity. Trials are identified by the first author names. ${ }^{11-24}$

trials of Gerstmann et al, Thome et al, and Johnson et al 121721 brought about the strongest changes of odds ratio towards unity. Common features of these trials were the introduction of strategies to improve ventilatory care for infants receiving CMV. Gerstmann et al ${ }^{12}$ used surfactant, in contrast to their predecessors, which may have benefited infants randomised to CMV more than those receiving HFV. Thome et $a l^{17}$ and Johnson et al ${ }^{21}$ emphasised the HFPPV strategy for CMV. ${ }^{2-4} 43$ Taken together, these findings indicate that whenever the CMV strategy was optimised, the advantage associated with HFV dwindled.

Two trials in this meta-analysis used synchronised ventilation with flow triggering for the CMV groups and found significantly better pulmonary outcomes with HFV. ${ }^{19} 20$ However, when synchronisation is performed by flow triggering, the additional dead space of the flow sensor will lead to larger tidal volumes than would be necessary otherwise, especially in very small infants. Synchronisation has not been found to improve pulmonary outcome in two large randomised trials ${ }^{43-45}$; the only study suggesting a better outcome by synchronised ventilation did not use flow triggering. ${ }^{46}$ Therefore, synchronised ventilation with flow triggering and rates of less than 60/min may not be the optimal choice for small premature infants, which may explain why HFV achieved a better outcome in these two trials.

There appeared to be an association between the overall outcome of the trials and the results of the comparisons between HFV and CMV. Studies finding an advantage associated with HFV generally had below average results with their CMV strategies (fig 4). A cumulative analysis with trials ordered by their control group event rate ${ }^{34}$ may further support this notion but would require correcting all trials by their large differences in baseline demographic variables. We felt that this would introduce too many statistical errors to be valid.

Trials finding no difference between HFV and CMV have been criticised for allowing too much exposure to CMV before starting $\mathrm{HFV} .{ }^{27}$ The cumulative meta-analysis with trials ordered by time to enrolment (fig 6) does not support this
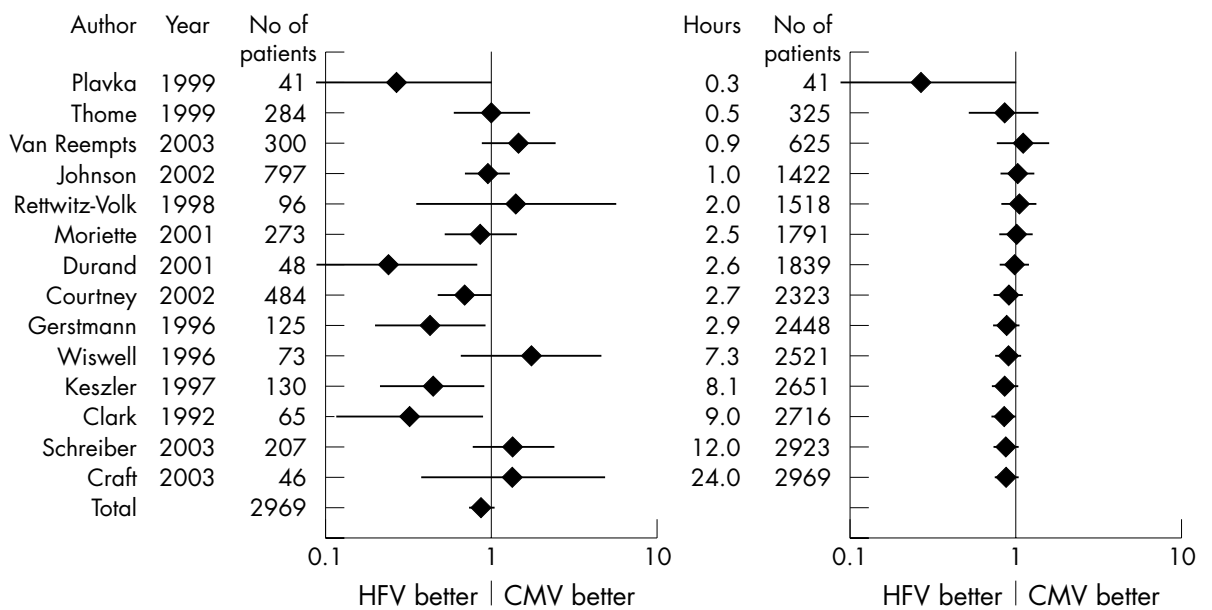

Figure 6 Cumulative meta-analysis with trials ordered by the delay before the start of the randomised ventilation mode. In the left panel, the odds ratios and $95 \%$ confidence intervals of individual trials are shown. In the right panel, the cumulative results are shown as follows: in the first line the results of the first trial, in the second line the combined results of the first two trials, and so on, until all trials are cumulated at the bottom of the panel. Trials are identified by the first author names and publication years. ${ }^{11-24}$ Total indicates overall result. Mean values of actual delays were used when reported, protocol limits were used otherwise. One trial not reporting any delay was set to $24 \mathrm{~h} .{ }^{22}$ 

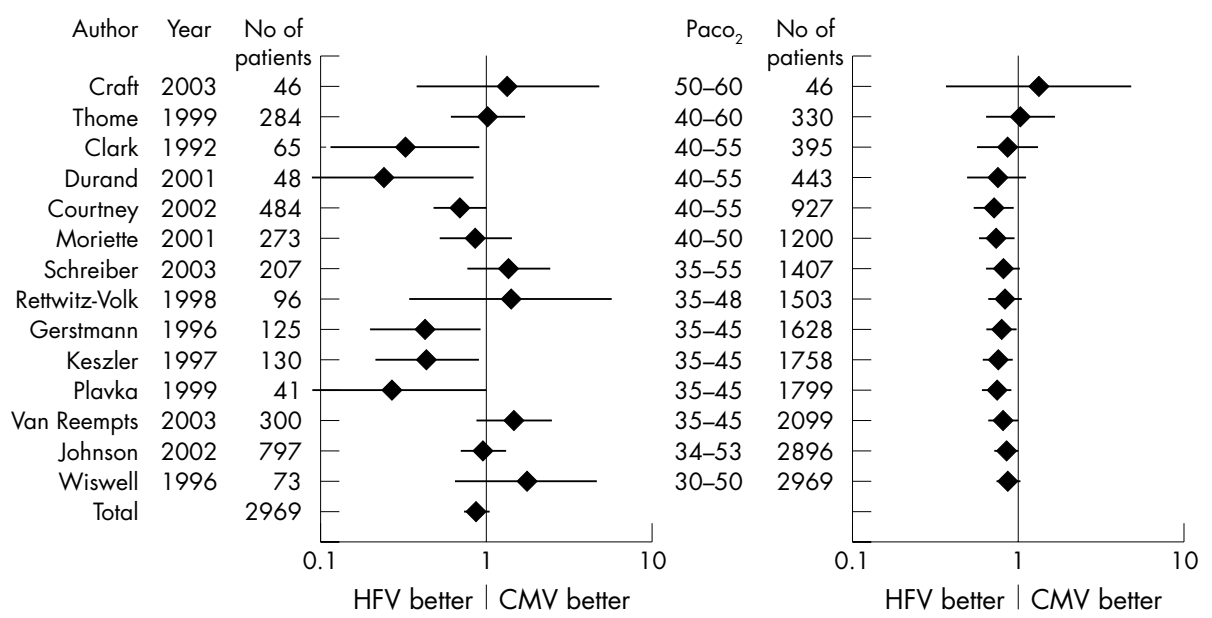

Figure 7 Cumulative meta-analysis with trials ordered first by the lower, then by the upper $\mathrm{Paco}_{2}$ limits as defined by the study protocols. In the left panel, the odds ratios and 95\% confidence intervals of individual trials are shown. In the right panel, the cumulative results are shown as follows: in the first line the results of the first trial, in the second line the combined results of the first two trials, and so on, until all trials are cumulated at the bottom of the panel. Trials are identified by the first author names and publication years. ${ }^{11-24}$ Total indicates overall result.

view, as the odds ratio values undulate around unity rather than showing clear patterns. ${ }^{34}$ Speculation that permissive hypercapnia may have influenced the outcome of HFV trials by benefiting infants on CMV more than those on $\mathrm{HFV}^{17}$ has also not been substantiated by a cumulative meta-analysis (fig 7). Likewise, the enrolled sample size was without a clear influence on the outcome difference between HFV and CMV (fig 8).

A significant increase in air leaks was associated with HFV. It was robust to the random effects analysis and also appeared in most subgroup analyses. Therefore, one can safely conclude that HFV as applied in most studies caused an increase in air leaks. Although most of these air leaks were probably radiological diagnoses without clinical sequelae, and were not followed by increased complications affecting long term health, such as severe IVH and BPD, this finding argues against routine use of HFV in the absence of clear benefits. More important than the outcome parameters discussed here would be long term follow up examinations. However, such data were only reported from three trials at different ages, ${ }^{47-51}$ and reflected the short term outcomes of the same trials. ${ }^{8} 1221$

One trial included in this meta-analysis ${ }^{24}$ used a factorial design randomising not only HFV or CMV but also inhaled nitric oxide and placebo. We included this trial as there was no interaction between the randomised ventilation mode and inhaled nitric oxide.

This meta-analysis also highlights the difficulties arising in situations where the available data consist of very heterogeneous studies. As in previous attempts, ${ }^{26} 323741$ the results of the significance tests depend on the selection of the studies for the subgroups, and the statistical models. The evidence obtained cannot be regarded as equivalent to level la. ${ }^{52}$

In conclusion, heterogeneity among trials of elective HFV in comparison to CMV in preterm infants appears to arise mainly from differences in ventilatory strategies. The time lag before enrolment and the use of permissive hypercapnia do not appear to influence study outcomes.

Optimising both modes, HFV by using an HLVS and CMV by using a high rate and minimal tidal volumes, appears to
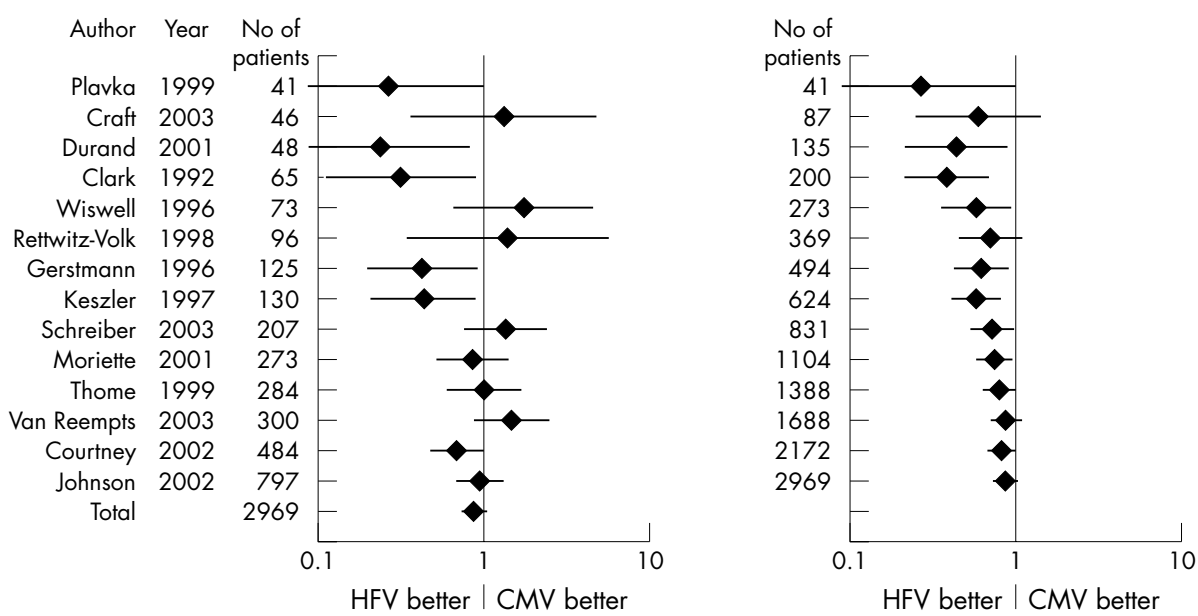

Figure 8 Cumulative meta-analysis with trials ordered by ascending sample size. In the left panel, the odds ratios and $95 \%$ confidence intervals of individual trials are shown. In the right panel, the cumulative results are shown as follows: in the first line the results of the first trial, in the second line the combined results of the first two trials, and so on, until all trials are cumulated at the bottom of the panel. Trials are identified by the first author names and publication years. ${ }^{11-24}$ Total indicates overall result. 


\section{What is already known on this topic}

- It is thought that ventilation with relatively large tidal volumes can result in lung injury

- Randomised controlled trials comparing elective use of high frequency ventilation with conventional mechanical ventilation in preterm infants have yielded conflicting results

\section{What this study adds}

- Optimising conventional mechanical ventilation strategy appeared to be as effective as high frequency ventilation in improving pulmonary outcome in preterm infants

- Purchasing costly HFV ventilators appears to be unnecessary for most neonatal intensive care units

lead to comparable outcomes. Therefore, meticulous attention to the ventilator settings seems to be more important than the choice of a particular mode or machine. Purchasing costly HFV ventilators appears to be unnecessary for most neonatal intensive care units. The use of HFV for rescuing patients with severe lung failure was beyond the scope of this review.

\section{ACKNOWLEDGEMENTS}

The authors thank Dr Michael D Schreiber for providing unpublished data from his study.

\section{Authors' affiliations}

U H Thome, F Pohlandt, Division of Neonatology and Pediatric Critical Care, University Hospital for Children and Adolescents, University of Ulm, Germany

W A Carlo, Division of Neonatology, Department of Pediatrics, University of Alabama at Birmingham, AL, USA

Competing interests: none declared

\section{REFERENCES}

1 Dreyfuss D, Saumon G. Ventilator-induced lung injury: lessons from experimental studies. Am J Respir Crit Care Med 1998;157:294-323.

2 Heicher DA, Kasting DS, Harrod JR. Prospective clinical comparison of two methods for mechanical ventilation of neonates: rapid rate and short inspiratory time versus slow rate and long inspiratory time. J Pediatr 1981;98:957-61

3 Oxford Region Controlled Trial of Artificial Ventilation (OCTAVE) Study Group. Multicentre randomised controlled trial of high against low frequency positive pressure ventilation. Arch Dis Child 1991;66:770-5

4 Pohlandt F, Saule H, Schröder H, et al. Decreased incidence of extra-alveolar air leakage or death prior to air leakage in high versus low rate positive pressure ventilation: results of a randomised seven-centre trial in preterm infants. Eur J Pediatr 1992;151:904-9.

5 Mariani G, Cifuentes J, Carlo WA. Randomized trial of permissive hypercapnia in preterm infants. Pediatrics 1999;104:1082-8.

6 Carlo WA, Stark AR, Wright LL, et al. Minimal ventilation to prevent bronchopulmonary dysplasia in extremely low birthweight infants. J Pediatr 2002;141:370-4.

7 The Acute Respiratory Distress Syndrome Network. Ventilation with lower tidal volumes as compared with traditional tidal volumes for acute lung injury and the acute respiratory distress syndrome. N Engl J Med 2000;342:1301-8.

8 HIFI Study Group. High-frequency oscillatory ventilation compared with conventional mechanical ventilation in the treatment of respiratory failure in preterm infants. N Engl J Med 1989;320:88-93.

9 Carlo WA, Siner B, Chatburn RL, ef al. Early randomized intervention with high-frequency jet ventilation in respiratory distress syndrome. J Pediat 1990; 117:765-70.
10 Ogawa Y, Miyasaka K, Kawano T, et al. A multicenter randomized trial of high frequency oscillatory ventilation as compared with conventional mechanical ventilation in preterm infants with respiratory failure. Early Hum Dev 1993;32:1-10.

11 Clark RH, Gerstmann DR, Null DM Jr, et al. Prospective randomized comparison of high-frequency oscillatory and conventional ventilation in respiratory distress syndrome. Pediatrics 1992;89:5-12.

12 Gerstmann DR, Minton SD, Stoddard RA, et al. The Provo multicenter early high-frequency oscillatory ventilation trial: improved pulmonary and clinical outcome in respiratory distress syndrome. Pediatrics 1996;98:1044-57

13 Wiswell TE, Graziani U, Kornhauser MS, et al. High-frequency jet ventilation in the early management of respiratory distress syndrome is associated with a greater risk for adverse outcomes. Pediatrics 1996;98:1035-43.

14 Keszler M, Modanlou HD, Brudno DS, et al. Multicenter controlled clinical trial of high-frequency jet ventilation in preterm infants with uncomplicated respiratory distress syndrome. Pediatrics 1997; 100:593-9.

15 Rettwitz-Volk W, Veldman A, Roth B, et al. A prospective, randomized, multicenter trial of high-frequency oscillatory ventilation compared with conventional ventilation in preterm infants with respiratory distress syndrome receiving surfactant. J Pediatr 1998;132:249-54.

16 Plavka R, Kopecky P, Sebron V, et al. A prospective randomized comparison of conventional mechanical ventilation and very early high frequency oscillatory ventilation in extremely premature newborns with respiratory distress syndrome. Intensive Care Med 1999;25:68-75.

17 Thome U, Kössel H, Lipowsky G, et al. Randomized comparison of high frequency ventilation with high rate intermittent positive pressure ventilation in preterm infants with respiratory failure. J Pediatr 1999;135:39-46.

18 Moriette G, Paris-Llado J, Walti H, et al. Prospective randomized multicenter comparison of high-frequency oscillatory ventilation and conventional ventilation in preterm infants of less than 30 weeks with respiratory distress syndrome. Pediatrics 2001;107:363-72.

19 Durand DJ, Asselin JM, Hudak ML, et al. Early high-frequency oscillatory ventilation versus synchronized intermittent mandatory ventilation in very low birth weight infants: a pilot study of two ventilation protocols. J Perinatol 2001;21:221-9.

20 Courtney SE, Durand DJ, Asselin JM, et al. High-frequency oscillatory ventilation versus conventional mechanical ventilation for very-low-birthweight infants. N Engl J Med 2002;347:643-52.

21 Johnson AH, Peacock JL, Greenough A, et al. High-frequency oscillatory ventilation for the prevention of chronic lung disease of prematurity. N Engl J Med 2002;347:633-42.

22 Craft AP, Bhandari V, Finer NN. The sy-fi study: a randomized prospective trial of synchronized intermittent mandatory ventilation versus a highfrequency flow interrupter in infants less than $1000 \mathrm{~g}$. J Perinatol 2003;23:14-19.

23 Van Reempts P, Borstlap C, Laroche S, et al. Early use of high frequency ventilation in the premature neonate. Eur J Pediatr 2003;162:219-26.

24 Schreiber MD, Gin-Mestan K, Marks JD, et al. Inhaled nitric oxide in premature infants with the respiratory distress syndrome. N Engl J Med 2003;349:2099-107.

25 Bryan AC, Froese AB. Reflections on the HIFI trial. Pediatrics 1991;87:565-7.

26 Thome UH, Carlo WA. High-frequency ventilation in neonates. Am J Perinatol 2000;17:1-9

27 Rimensberger PC, Beghetti M, Hanquinet S, et al. First intention highfrequency oscillation with early lung volume optimization improves pulmonary outcome in very low birth weight infants with respiratory distress syndrome. Pediatrics 2000; 105:1202-8.

28 Clark RH, Gerstmann DR. Controversies in high-frequency ventilation. Clin Perinatol 1998;25: 113-22.

29 McCulloch PR, Forkert PG, Froese AB. Lung volume maintenance prevents lung injury during high frequency oscillatory ventilation in surfactant-deficient rabbits. Am Rev Respir Dis 1988; 137:1185-92.

30 Froese $A B, M c C u l l o c h$ PR, Sugiura $M$, et al. Optimizing alveolar expansion prolongs the effectiveness of exogenous surfactant therapy in the adult rabbit. Am Rev Respir Dis 1993;148:569-77.

31 Sugiura M, McCulloch PR, Wren S, et al. Ventilator pattern influences neutrophil influx and activation in atelectasis-prone rabbit lung. J Appl Physiol 1994;77:1355-65.

32 Henderson-Smart DJ, Bhuta T, Cools F, et al. Elective high frequency oscillatory ventilation versus conventional ventilation for acute pulmonary dysfunction in preterm infants. Cochrane Database Syst Rev 2005;3:CD000104.

33 Bhuta T, Henderson-Smart DJ. Elective high frequency jet ventilation versus conventional ventilation for respiratory distress syndrome in preterm infants. Cochrane Database Syst Rev 2005;3:CD000328

34 Lau J, Schmid CH, Chalmers TC. Cumulative meta-analysis of clinical trials builds evidence for exemplary medical care. J Clin Epidemiol 1995:48:45-57.

35 loannidis JP, Contopoulos-loannidis DG, Lau J. Recursive cumulative metaanalysis: a diagnostic for the evolution of total randomized evidence from group and individual patient data. J Clin Epidemiol 1999;52:281-91.

36 loannidis J, Lau J. Evolution of treatment effects over time: empirical insight from recursive cumulative metaanalyses. Proc Natl Acad Sci U S A 2001;98:831-6.

37 Bollen CW, Uiterwaal CSPM, van Vught AJ. Cumulative metaanalysis of highfrequency versus conventional ventilation in premature neonates. Am J Respir Crit Care Med 2003; 168:1150-5.

38 Papile LA, Burstein J, Burstein R, et al. Incidence and evolution of subependymal and intraventricular hemorrhage: a study of infants with birth weights less than 1,500 gm. J Pediatr 1978;92:529-34. 
39 Mantel N, Haenszel W. Statistical aspects of the analysis of data from retrospective studies of disease. J Natl Cancer Inst 1959;22:719-48.

40 DerSimonian R, Laird N. Meta-analysis in clinical trials. Control Clin Trials 1986:7:177-88.

41 Cools F, Offringa M. Meta-analysis of elective high frequency ventilation in preterm infants with respiratory distress syndrome [see comments]. Arch Dis Child Fetal Neonatal Ed 1999;80:F15-20.

42 Lombet J, Claris O, Debauche C, et al. High frequency oscillation versus conventional mechanical ventilation for respiratory distress syndrome. Pediatr Res 1996;40:540.

43 Greenough A, Milner AD, Dimitriou G. Synchronized mechanical ventilation for respiratory support in newborn infants. Cochrane Database Syst Rev 2005; 3:CD000456.

44 Baumer JH. International randomised controlled trial of patient triggered ventilation in neonatal respiratory distress syndrome [see comments]. Arch Dis Child Fetal Neonatal Ed 2000;82:F5-10.

45 Beresford MW, Shaw NJ, Manning D. Randomised controlled trial of patient triggered and conventional fast rate ventilation in neonatal respiratory distress syndrome [see comments]. Arch Dis Child Fetal Neonatal Ed 2000;82:F14-18.
46 Bernstein G, Mannino FL, Heldt GP, et al. Randomized multicenter tria comparing synchronized and conventional intermittent mandatory ventilation in neonates [see comments]. J Pediatr 1996;128:453-63.

47 HIFI Study Group. High-frequency oscillatory ventilation compared with conventional mechanical ventilation in the treatment of respiratory failure in preterm infants: assessment of pulmonary function at 9 months of corrected age. J Pediatr 1990;1 16:933-41.

48 HIFI Study Group. High-frequency oscillatory ventilation compared with conventional intermittent mechanical ventilation in the treatment of respiratory failure in preterm infants: neurodevelopmental status at 16 to 24 months of postterm age. J Pediatr 1990; 117:939-46.

49 Pianosi PT, Fisk M. High frequency ventilation trial. Nine year follow up of lung function. Early Hum Dev 2000;57:225-34.

50 Gerstmann DR, Wood K, Miller A, et al. Childhood outcome after early highfrequency oscillatory ventilation for neonatal respiratory distress syndrome. Pediatrics 2001; 108(3):617-23.

51 Thomas MR, Rafferty GF, Limb ES, et al. Pulmonary function at follow-up of very preterm infants from the United Kingdom Oscillation Study. Am J Respir Crit Care Med 2004; 169:868-72.

52 Phillips B, Ball C, Sackett D, et al. Levels of evidence and grades of recommendation. hitp://www.cebm.net/levels_of_evidence.asp, 2004

\section{Clinical Evidence - Call for contributors}

Clinical Evidence is a regularly updated evidence-based journal available worldwide both as a paper version and on the internet. Clinical Evidence needs to recruit a number of new contributors. Contributors are healthcare professionals or epidemiologists with experience in evidence-based medicine and the ability to write in a concise and structured way.

Areas for which we are currently seeking authors:

- Child health: nocturnal enuresis

- Eye disorders: bacterial conjunctivitis

- Male health: prostate cancer (metastatic)

- Women's health: pre-menstrual syndrome; pyelonephritis in non-pregnant women

However, we are always looking for others, so do not let this list discourage you.

Being a contributor involves:

- Selecting from a validated, screened search (performed by in-house Information Specialists) epidemiologically sound studies for inclusion.

- Documenting your decisions about which studies to include on an inclusion and exclusion form, which we keep on file.

- Writing the text to a highly structured template (about 1500-3000 words), using evidence from the final studies chosen, within 8-10 weeks of receiving the literature search.

- Working with Clinical Evidence editors to ensure that the final text meets epidemiological and style standards.

- Updating the text every six months using any new, sound evidence that becomes available. The Clinical Evidence in-house team will conduct the searches for contributors; your task is simply to filter out high quality studies and incorporate them in the existing text.

- To expand the topic to include a new question about once every 12-18 months.

If you would like to become a contributor for Clinical Evidence or require more information about what this involves please send your contact details and a copy of your CV, clearly stating the clinical area you are interested in, to Klara Brunnhuber (kbrunnhuber@ bmigroup.com).

\section{Call for peer reviewers}

Clinical Evidence also needs to recruit a number of new peer reviewers specifically with an interest in the clinical areas stated above, and also others related to general practice. Peer reviewers are healthcare professionals or epidemiologists with experience in evidence-based medicine. As a peer reviewer you would be asked for your views on the clinical relevance, validity, and accessibility of specific topics within the journal, and their usefulness to the intended audience (international generalists and healthcare professionals, possibly with limited statistical knowledge). Topics are usually 1500-3000 words in length and we would ask you to review between 2-5 topics per year. The peer review process takes place throughout the year, and our turnaround time for each review is ideally 10-14 days.

If you are interested in becoming a peer reviewer for Clinical Evidence, please complete the peer review questionnaire at www.clinicalevidence.com or contact Klara Brunnhuber (kbrunnhuber@bmigroup.com). 